\title{
New Retail: A Conversion of Business Mode from Online-To- Offline (O2O) to the Online-Merge-Offline (OMO)
}

\author{
Xinyu Yang * \\ Division of Science and Technology United International College, Zhuhai, China \\ *n830026139@mail.uic.edu.cn
}

\begin{abstract}
This research analyzes the reasons for the emergence of the conversion from Online-toOffline to Online-to-Offline. A comparative model and case study, focusing on the successful outcome of Kellogg's café and Pure Leaf, on the one hand, shows the advantages of the new offline experience store, while on the other hand, the feedback from $\mathrm{CiCi}$ Park visitors reminds the uncertainty of this merging strategy.
\end{abstract}

Keywords: Conversion; Online-Merge-Offline; Online-To-Offline; Experience.

\section{Introduction}

In 2016, Jack Ma, founder and chairman of e-commerce giant Alibaba, coined the term "New Retail" to describe how offline, online, and logistics businesses were merging to create an integrated retail model which offering a new shopping experience without boundaries [1]. This paper explores whether this new commercial mode will take the place of the traditional business mode (i.e., O2O) and bring more profits to the retail industry.

Over the past few years, the majority of retailers have isolated their physical store and the Internet store from each other. The information in these two divisions is difficult to be unified and integrated, which makes the profit of the enterprise stagnant. Let's take a look at the conditions of online and offline in recent years, respectively.

Statistics on total retail sales and online retail sales of consumer goods in China from 2014 to 2019

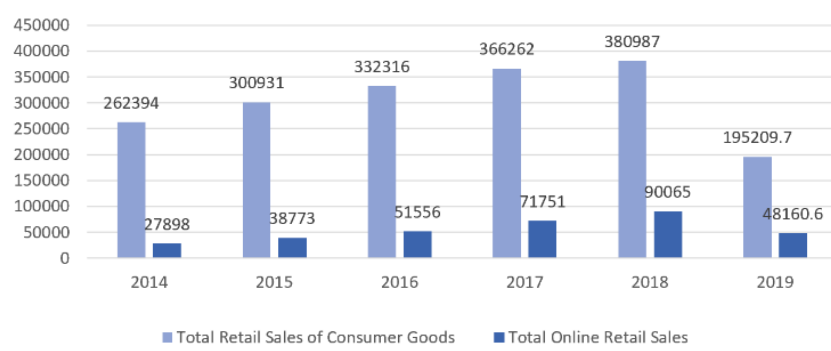

Figure 1. Statistics on total retail sales and online retail sales of consumer goods in China from 2014 to 2019

According to public data from 2014-2019, with the Chinese market as a typical example, ecommerce accounts for less than a quarter of the country's total retail sales, which shows that offline stores are an indispensable and predominant part of people's life. In recent years, however, with the crazy expansion of online e-commerce and the emergence of e-commerce live streaming, coupled with the heavy blow of the epidemic (COVID-19), we find that it seems physical stores all over the world are closing, or even bankrupt. Fast fashion brands such as Gap and HM are not able to resist the trend. Moreover, super-sports brands such as Nike and Adidas are also not escaped from this disaster. Even the luxury brands such as Chanel and top popular fashion brands such as Supreme have all begun to cut marketing budgets, apply for government financial aid, and close stores on a large scale. During the period of the epidemic, the pace of economic recovery in various sectors has 
accelerated. We are surprised to see that some brands are constantly adjusting their marketing strategies in the face of the challenges brought by these epidemic, and countless brands have opened online flagship stores and joined the e-commerce live streaming army. There are such as Burberry, Dior and other luxury brands opened Tik Tok, Bilibili, and other live streaming platform accounts. With Chanel opened an online conference and Gucci's live streaming fashion show, we seem to have such a puzzling feeling, are offline stores really going out of business?

Nevertheless, the reversal occurred again. In the post-epidemic era, when they are not optimistic about the offline consumption scene, more and more brands are "Start in the back " and begin to transform offline stores with great efforts by providing in-store online terminals in a physical store and assortment availability information on the Internet, and have achieved positive results. It seems like that the trend of online and offline integration is gradually emerging.

Thus, in this paper, we try to figure out the impact of the new retail, and address the following questions:

Does the merging of online-offline channel lead to a competitive advantage for the retailers?

What does the new retail model bring to consumers?

What are the real demands of consumers nowadays?

A case study based on Coca-Cola new retail plan and some comparative models will be provided in this study to answer these questions.

\section{Data and Method}

With the change of market environment, the connection points between brands and consumers have become more diversified. In order to get closer to consumers and establish a more direct and meaningful emotional connection, food and beverage brands have started different attempts. The previous business model is gradually changing. Creating a multi-channel consumption experience that integrates online and offline has become a new strategy. Thus, this paper uses comparative models and cases to analyze the reaction of different beverage retailers to see how they merge the online-channel and offline channel and get profits from this new retail.

\subsection{Study1}

The purpose of Study 1 is to test whether and how the new retail can lead to a competitive advantage for retailers. As mentioned above, offline-channel and online-channel have a converging trend. For instance, Kellogg's NYC, Pure Leaf Tea House Café, Chobani SoHo and Chobani TriBeCa etc. No matter it is permanent or flash mob, it seems to be a prevalent practice in the food and beverage industry today. Thus, in this study, we try to explore this interesting phenomenon that more and more FMCG (fast-moving consumer goods) brands have started offline experience stores and try to figure out the difference of in-store products and services between traditional retail and the new retail by visiting the US market deeply [2].

\subsubsection{Kellogg's NYC and Pure Leaf Tea House Café}

Kellogg has a Cyal Cafe in New York's Times Square, which opened in July 2016, located in the most prosperous area of New York City, with a huge number of passengers and attendance. The Grain Cafe Experience is more like an old town oasis in the middle of a busy New York City. A variety of consumers' favorite breakfast cereal bowls are available 24/7. You can add full-fat or low-fat milk for free, as well as yogurt, soft-serve ice cream, or smoothies, for an extra $\$ 2$ to $\$ 4$. After placing an order, a buzzer is handed over, and when the cereal bowl is ready, it is presented through a selfservice pickup counter on the wall, with a number that corresponds to the number on the pager. Once should be mentioned is that these self-service pickup counters often play a trick on users by opening them to reveal not exactly cereal bowls, but perhaps a toy, a week's worth of Uber steering drivers, or tickets to the new Broadway musical. Kellogg also designed some peripheral products for customers to choose from when they are waiting for their food [3]. 
Above all, in order to overcome the problem that grain sales have been declining in recent years, Kellogg has been looking for new ways to reach more users, especially millennials. This experience store is a bold change of Kellogg to the traditional retail channels. It matches its main cereal and grain products with richer combinations of fruit and candy, bringing people a more diversified consumption experience and enhancing customer stickiness.

Pure Leaf, a brand owned by the joint venture of PepsiCo united Unilever, also make a similar attempt. They set up a flash mod store, Pure Leaf Tea House Café, in Soho district, New York, which opened on June 28 and closed on September 24. This physical store gives people a fresh, natural, quiet feeling. The overall style is simple, elegant. When customers came in, they would first see a brand and tea display area, a long bar, and then a small lounge area. Once keep going inside, people find the Tea Scent Artium, an elaborate museum-style museum that tells the story of Tea's history and consumption. Here, they can enjoy a variety of forms of brewed handmade tea and exotic tea drinks, from freshly made iced tea, hot tea to tea bags, from Indian tea, Japanese tea, and American tea. Flavors like apple, lemon, mint, and Kenya purple tea with berries; There are also some teas that offer free food pairings, such as delicious popcorn teas, paired with sweet popcorn, provide a rich mouth-feel experience. Professional tea makers prepare all kinds of tea, and the whole process is very similar to the way cocktails are prepared. This shop is creative enough to make tea as a cocktail. Ice tea is the flagship of the store, so we ordered two cups, appreciate the whole ice tea production, the process of adding tea concentrate, ice syrup, followed by a series of stunning wine, then add lemon slices respectively, mint, ice cubes, add a few drops of Martell, a cup of iced tea was so coveted.

Pure Leaf, which emphasizes premium quality, uses USDA-certified organic teas and is brewed from real tea leaves in small batches, rather than from powdered tea or concentrate. The Tea leaves are meticulously blended with fresh Tea picking, steeped and brewed by Pure Leaf's Tea Masters team for the ultimate mellow flavor. The purpose of such a Tea house is to publicize and emphasize the brand concept and product concept, so that consumers can have a close experience of the production process of a cup of Tea, from the real material to the careful preparation, so as to convey the brand image of natural, pure, healthy and carefully brewed Tea [4].

\subsubsection{Discussion of the Above Two Cases}

After analyzing two physical stores, we think about why more and more brands open offline experience stores. What's the point of them doing this? What is the main driving force behind this? We will analyze it from the following four aspects:

(1) The ultimate experience brings high user stickiness

Without exception, these offline experience stores use a variety of "small thoughts" to improve the user's consumption experience, so that you can feel a kind of comfort brought by quality life in those niceties.

From the perspective of environment and design, the obvious common feature of these offline stores is that the distinctive packaging or space design style highlights the brand image, which is different from that in general retail channels or grocery stores so that the brand can easily stand out and leave an impression on consumers. For example, Kellogg's NYC uses bright red, Pure Leaf Tea House uses green and black, and Chobani Soho uses transparent glass Windows and logs. When you walk into a store, there is a feeling of suddenly slowing down, of getting away from the hustle and bustle of the city, of being immersed in the environment and enjoying the pleasure of a healthy life.

From the point of view of product experience, the constant is the quality of the product, the form of the product is changeable. For example, Chobani Cafe has a wide variety of menu forms, ranging from sweet to savory, from breakfast to baked snacks, with yogurt everywhere, beyond our imagination, and many products that are not available through traditional retail channels. In Kellogg's Grain Cafe, consumers can directly purchase grain bowls with a fixed menu or make them according to their own preferences and try a variety of new flavors of grain bowls. Besides, NoelGeoffroy, Kellogg's senior vice president of breakfast food marketing and innovation, has said that the company's plan is to update the menu every quarter to keep it fresh and to incorporate seasonal flavors 
and ingredients into cereal bowl recipes. Such product experience meets the diverse needs of consumers for product categories, forms, and tastes.

From the point of view of service, whether it is Chobani's handsome running brother, from ordering, food delivery to service all the work; Pure Leaf's professional tea makers make tea drinks like cocktails; It's the little surprises that pop up from time to time in Kellogg's self-service locker... It can always make people feel a sense of welcome, distance, and self-improvement in the process of consumption.

Through these designs, menus, products and services, every detail allows consumers to experience the "Who are we and what are our products? What do we want to offer the consumer?" which help the brands leave a deep impression on customer's mind.

(2) Speak for the brand, communicate directly with customers and tell the brand story

Skip the traditional retail channels or media. These offline experience stores establish a more direct way of communication with consumers, speak for the brand and convey its values, and provide a form of new experience for consumers. Obviously, they are also trying to create a healthy lifestyle that is socially friendly and reflects the brand image in a number of ways, such as, fresh and healthy formula, high appearance level products, thoughtful design and service, etc. Especially for today's millennial generation of young consumers, it is very easy to be infected and willing to share such content on social media to deliver brand value.

The 280-square-meter space behind Pure Leaf's Tea House in SoHo is more about promoting the brand and product, telling the story behind it, and delivering a value proposition than generating significant sales profits. Given rental costs in Manhattan, brands are less concerned with how much they spend to open a store or how much they make, and more focused on the value and meaning they bring to the brand beyond profit.

As Laraine Miller, Pure Leaf's senior marketing director, previously said in an interview, In terms of return on investment, that's not what we set up the store for and that's not how we think about it. Here, each Pure Leaf product demonstrates its passion and professionalism to consumers, which is a healthy lifestyle attitude. Consumers value the different sensory enjoyment brought by real brewing. We hope that this Tea House can provide a different Tea drinking experience.

(3) New product concept testing, effective access to the real needs of consumers

Brand experience shop is given in the form of bigger play space, some inconvenient in retail channels for direct selling products, but can undertake various attempts, here to provide brand new product concept testing opportunities and conditions, can be more immediate two-way communication with the consumer, more convenient and effective to obtain the real demand of consumers.

In February of this year, Kellogg's classic brand and product, Pop-Tarts, had a week-long pop-up at the store in New York. Try nearly 20 different flavors and recipes of Pop-Tarts in one go, like birthday cake, burritos, salads, coffee, drinks, breadcrumbs, yogurt, etc.

Peter McGuinness, the chief marketing officer of Chobani, once said, Chobani Cafe is a concept test kitchen and innovation center. Every consumer is the target of our ideas incubation and inspiration implementation. The opportunity to interact directly with them, inspire them, and be inspired by them on a daily basis is the essence of a branded cafe.

The Chobani Experience Store's innovative idea is to use this new form of direct interaction with consumers to test new concepts of yogurt products. The Chobani Flip, designed as an afternoon tea snack and packaged in separate pieces, is a product from Cafe to a supermarket. Currently, there are nearly 30 flavors in the Flip line, most of which are inspired by Chobani Cafe.

(4) Sales growth from experiential marketing

These stores are another window for brands to showcase their services and sell their products. For example, at the Chobani Cafe, ready-made Yogurt comes from Chobani's special catering tubs, including its Yogurt Bowls, sandwiches, baking products, and even dessert puddings. And there will be special window displays to showcase some of Chobani's top sellers in other retail channels and online. 
Taste, experienced, will also likely be brand loyal consumers in other channels. Chobani Cafe is to expand and extend the meaning of user way of eating yogurt and scene, enhance their consumer experience, to promote higher sales growth, which is one of the main aims of experiential marketing.

Fortune reported that since Chobani opened his first SoHo Cafe in New York City, the company's sales have increased 40 percent. The first Chobani Cafe opened in 2012 and doubled in size the following year. Opened a second Chobani Tribeca in 2016; In 2007, it opened a third, in the Woodlands, Tomball, Texas, in a larger, 180-square-meter Walmart mall next door. Perhaps it has tasted this kind of sweet, so it is still expanding the layout step by step.

Generally speaking, these traditional and emerging brands may have different original intentions to open offline experience stores, but they are all trying to understand and capture the real needs of consumers from the most realistic consumption scenarios, which is the most valuable reference for us to do product innovation.

\subsection{Study2}

The same phenomenon exists in China too. Therefore, in the following case, we will treat Chinese market and its pioneer as an example.

\subsubsection{Data Pre-processing}

Study 2 shows that not all kinds of physical stores will bring a good experience for consumers. Sometimes it may have the opposite effect. The study focuses on emerging popularity of physical activity store in China, Coca-Cola World-CICI PARK. Therefore, we crawled 345 reviews from dianping which is an $\mathrm{O} 2 \mathrm{O}$ planform in China to do the sentiment analysis and drew the word cloud based on the word frequency [5]. We do some Pre-processing of these comments and set threshold equals to 40 , finally we extracted the top 55 commonly used words to draw the word cloud. The size of word represents the occurrence frequency of the word and the larger the word, the higher the word frequency.

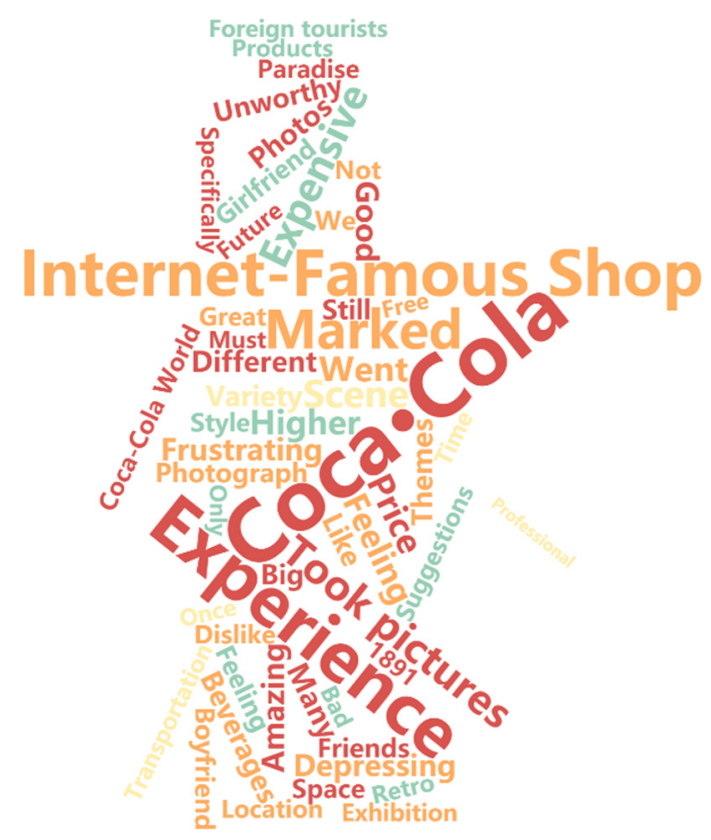

Figure 2. Word cloud

\subsubsection{Analysis and Results}

The most obvious words in the picture are "Internet-famous shop", "Coca-Cola", "experience" and "took picture". "Marked", "higher", "price", "frustrating", "feeling", "depress", "amazing" and "expressive" are followed by. We can find that people's positioning of CICI PARK, as the company hopes, is generally a location where Internet celebrities often show up or visit. People go for a novel 
experience to entertain themselves. At the same time, we can see the words like "amazing" and "professional", indicating that people are very satisfied with this experience store's creativity. However, people also had a negative impression on CiCi Park. The modifiers of "price" are "higher", "frustrating", and "expressive", this indicates that people did not think the experience was very costeffective. Meanwhile, the words in the cloud relating to feelings are "depress" and "frustrating", which means the museum's experience to the customer's feelings are dissatisfied. Overall, the costeffective is very low, although it is creative, customers said this would be the only once travel in their life.

\subsubsection{Discussion of Study 2}

Based on customers' experience comments, retailers have to reflect that although it is a good thing to set up a creative offline-channel, they also need to consider the outcome, that is, whether this experience can bring competitive advance for their brand.

\section{Conclusion}

The traditional retail business model only includes offline entities such as supermarkets, hypermarkets and convenience stores. But with the development of e-commerce, online stores have attracted more attention. The new retail organically integrates offline and online resources and promotes the sound development of business forms and the innovation of transaction methods, which provides better products and services for consumers.

All in all, the new retail is an upgrade and innovation on the basis of the traditional retail industry, without a subversive change. With the support of artificial intelligence, big data, and cloud computing, it promotes the organic integration of offline and online, improves consumer experience and value creation, and integrates the omni-channel supply chain. At the same time, with the help of electronic payments and social media marketing, it has promoted consumption upgrading, improved efficiency, and helped retailers to improve the offline service quality and decrease the risk perceptions of onlinechannel. In addition, it provided consumers with a way of cross channel shopping simultaneously using multiple channels in order to meet their needs for a seamless shopping experience for shopping, entertainment, and social interaction. Thus, it can be seen that the conversion of the traditional retail model has formed an inevitable trend.

\section{References}

[1] The New Retail Revolution. (September, 2019). Retrieve from: CGAP: https:// www.cgap. org/research/ publication/new-retail-revolution.

[2] Passy, C. (July 11, 2017). Consumer Brands Set Up NYC Pop Up Stores to Create Buzz. Retrieve from: THE WALL STREET JOURNAL: https://www.wsj.com/articles/in-new-york-consumer-brands-wantto-be-a-part-of-it-1499809204.

[3] Buss, D. (October 10, 2019). Why Is Big Food Touting its Brands with Pop-Up Stores? Retrieve from: INTEGRATED RESEARCH: http://integratedresearch.com/big-food-touting-brands-pop-stores/.

[4] Mannering, C. (July 19, 2017). Want a cup of popcorn tea? CPG brands roll out pop-up stores. Retrieve from: FOODDIVE: https://www.fooddive.com/news/want-a-cup-of-popcorn-tea-cpg-brands-roll-outpop-up-stores/447062/.

[5] dianping. (2020). Retrieve from: CiCiPARK http://www.dianping.com/shop/G1MrSicDjwFnT2sX. 